\title{
A REASSESSMENT OF THE TAXONOMIC VALIDITY OF DYNAMOTERROR DYNASTES (THEROPODA, TYRANNOSAURIDAE)
}

\author{
Chan-gyu Yun \\ Vertebrate Paleontological Institute of Incheon, Incheon 21974, Republic of Korea, \\ Biological Sciences, Inha University, Incheon 22212, Republic of Korea \\ E-mail: changyu1015@naver.com
}

Chan-gyu Yun (https://orcid.org/00000-0002-2158-7918)

\begin{abstract}
A Reassessment of the Taxonomic Validity of Dynamoterror dynastes (Theropoda, Tyrannosauridae). Chan-gyu Yun. - Associated fragmentary materials of tyrannosaurid theropod Dynamoterror dynastes McDonald et al., 2018, were reported from the Upper Cretaceous Menefee Formation of New Mexico. However, two originally proposed autapomorphies (i. e. prefrontonasal and prefrontolacrimal processes separated by a shallow notch; subrectangular caudal postorbital suture separated from the rostral part by a deep groove) for Dynamoterror are present in other tyrannosaurids, and the poorly preserved nature of the holotype frontal makes it uncertain whether these features are even comparable to other tyrannosaurids. Thus, the combination of inadequacy of autapomorphies and the highly fragmentary nature of the holotype means that the taxonomic name should be regarded as a nomen dubium. Key words: Theropoda, Tyrannosauridae, Dynamoterror, nomen dubium.
\end{abstract}

\section{Introduction}

Tyrannosaurid theropods were carnivorous dinosaurs famous for having exceptionally large body size, deep skulls with robust teeth, extremely reduced forelimbs and elongated hindlimbs (e. g., Holtz, 2004; Brusatte et al., 2010). The current fossil record of these theropods is largely restricted to the Upper Campanian and Maastrichtian strata of North America and Asia (Currie, 2003; Holtz, 2004), though time-calibrated phylogenetic analyses suggest an earlier origin of this clade, likely between 90 and $80 \mathrm{Ma}$ (e. g., Nesbitt et al., 2019; Zanno et al., 2019).

Unfortunately, however, the pre-Campanian and early Campanian tyrannosaurid fossil record is poorly known and most of them consist of isolated teeth (e. g., Dalman and Lucas, 2018). The oldest definite tyrannosaurid theropod confirmed so far is Lythronax argestes Loewen et al., 2013 from the Wahweap Formation of Utah, as the sediments of the quarry which the holotype excavated were radioisotopically dated as between 80.75 and $79.60 \mathrm{Ma}$ (Loewen et al., 2013). The next geologically oldest tyrannosaurid taxon is Thanatotheristes degrootorum Voris et al., 2020 from the Foremost Formation of Alberta, found in sediments that are about 79.50 Ma (Voris et al., 2020). Although small in number, these taxa offer significant implications for understanding early stages of evolution of tyrannosaurid theropods. 
In 2012, fragmentary associated materials of a tyrannosaurid theropod were excavated from the upper part of the Allison Member, Menefee Formation (Lower Campanian) of New Mexico which is estimated to be between 80 and $79 \mathrm{Ma}$ (McDonald et al., 2018). Thus, McDonald et al. (2018) assumed that these materials were from the same individual, and assigned them to a new genus and species of tyrannosaurid theropod, Dynamoterror dynastes. The designated type specimen of Dynamoterror, UMNH VP 28348, consists of a pair of frontals, four partial vertebrae, fragments of ribs, ilium, metacarpal, pedal phalanges and unidentified bones, though this taxon was erected based on two proposed autapomorphies of a frontal.

However, a comparative examination of frontals of UMNH VP 28348 and other tyrannosaurid frontals reveals that while partial eroded frontals do indeed suggest a tyrannosaurine affinity, the current type specimen is insufficient to base a taxon on as the proposed autapomorphies actually present in other tyrannosaurid specimens and the poorly preserved nature of the specimen makes it difficult for morphological descriptions of those proposed characters. Here, the author reviews each autapomorphy of Dynamoterror proposed by McDonald et al. (2018).

\section{Institutional abbreviations}

BYU, Brigham Young University; CMN, Canadian Museum of Nature; SDNHM, San Diego Natural History Museum; TMP, Royal Tyrrell Museum of Palaeontology; UMNH, Natural History Museum of Utah.

\section{Comments on proposed diagnostic features}

The original diagnosis proposed by McDonald et al. (2018) was based on two characters of the frontal bone: (1) prefrontonasal and prefrontolacrimal processes are in close proximity, separated only by a shallow notch; (2) subrectangular, concave, laterally projecting caudal part of the postorbital suture separated from the rostral part by a deep groove. However, these proposed autapomorphies are inadequate based on the following reasons.

Prefrontonasal and prefrontolacrimal processes are in close proximity, separated only by a shallow notch.

McDonald et al. (2018) described this character as unique to UMNH VP 28348 and thus as an autapomorphy for Dynamoterror. However, a nearly identical morphology can be observed in an isolated right frontal (SDNHM 32701) that is assignable to Daspletosaurus torosus Russell, 1970 (pers. obs.; fig. 1). In SDNHM 32701, a small, conical prefrontonasal process is separated from the small prefrontolacrimal process only by a narrow, slight notch between them. Two processes in both specimens are nearly identical in morphology, and the depth of notch between them is comparable with each other (SDNHM 32701: $8 \mathrm{~mm}$; UMNP VP 28348: $7 \mathrm{~mm}$ ). The close proximity of two processes with a shallow notch between them is present in at least one other specimen (TMP 80.16.924) of Daspletosaurus torosus (Currie, 1987: fig. 1, g). Additionally, a prefrontolacrimal process of a right frontal in UMNH VP 28348 is slightly broken (McDonald et al., 2018; pers. obs.) so it is hard to evaluate how close these processes were originally placed, or the depth and morphology of the notch are comparable to other tyrannosaurids.

Another issue is that whether the morphology of suture between the frontal and nasal/prefrontal is a reliable feature for distinguishing tyrannosaurid taxa. Brochu (2003) considered the differences of configuration of such sutures among tyrannosaurid specimens rather represent taphonomic variabilities rather than phylogenetic signals. Indeed, a considerable amount of variations can be observed in Daspletosaurus torosus frontals: in the holotype (CMN 8506), separation between the prefrontonasal and prefrontolacrimal process is not prominent and only very subtle, rounded and wide notch is present between them (Russell, 1970; Currie, 1987: fig. 1, h). In SDNHM 32701, a narrow, slight notch separates these processes. Lastly, a deep, rounded notch separates two processes in TMP 2001.036.0001 (Voris et al., 2020: fig. 8, b). Similar variations can be observed between 
A

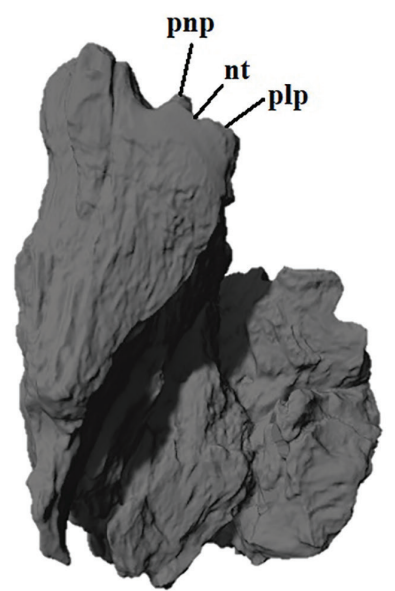

B

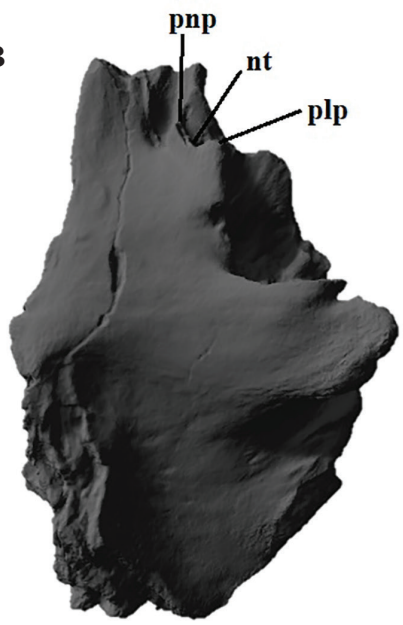

Fig. 1. Frontal bones of tyrannosaurid theropods in dorsal view, scaled to same total length. A, the right frontal of Dynamoterror dynastes UMNH VP 28348 in dorsal view. B, the right frontal of Daspletosaurus torosus SDNHM 32701 in dorsal view. Abbreviations: nt, notch between prefrontolacrimal and prefrontonasal processes; plp, prefrontolacrimal process; pnp, prefrontonasal process.

multiple Gorgosaurus libratus Lambe, 1914 specimens as well (Currie, 1987, 2003; Voris et al., 2019). In summary, the close position of these two processes and the presence of a shallow notch between them cannot be an autapomorphy of Dynamoterror as nearly identical condition occurs in Daspletosaurus torosus, and such configuration might represent individual or ontogenetic variation rather than phylogenetic.

Subrectangular, concave, laterally projecting caudal part of the postorbital suture, separated from the rostral part by a deep groove.

McDonald et al. (2018) described subrectangular, concave, laterally projecting caudal postorbital suture and a deep groove rostral to it as apomorphic for Dynamoterror frontals, and asserted that other tyrannosaurids have continuous rostral and caudal parts of the postorbital suture.

However, laterally facing subrectangular caudal part of postorbital suture with a deep groove rostral to it is observable in the right frontal BYU 8120/9396, a Teratophoneus curriei Carr et al., 2011 specimen (contra McDonald et al., 2018; fig. 2). The depth of a groove in BYU 8120/9396 $(12 \mathrm{~mm})$ and UMNH VP $28348(10 \mathrm{~mm})$ are compatible. Additionally, rectangular shape of the postorbital suture is typical for adults of tyrannosaurids (Bever et al., 2013).

Individual variation of morphology of a groove separating two parts of the suture is observed in Teratophoneus: in the right frontal BYU 8120/9396, the groove is narrow, deep and sulcus-shaped, whereas in the left frontal UMNH VP 16690, only a wide circular depression is present (fig. 2). Asymmetry of morphology and depth of postorbital suture and groove is present in frontals of UMNH VP 23438. In the left frontal, a groove is dorsoventrally shorter and the caudal postorbital suture is rounder and larger than those of the right frontal (pers. obs.), though some of these may be a taphonomic distortion (cf. McDonald et al., 2018). Therefore, this character is inadequate to be considered as an autapomorphy due to its presence in other tyrannosaurid taxon, and its dubious nature as taxonomically informative due to a high degree of variation. In fairness to McDonald et al. (2018), these authors also acknowledged the potential unreliability of this supposed autapomorphy. 

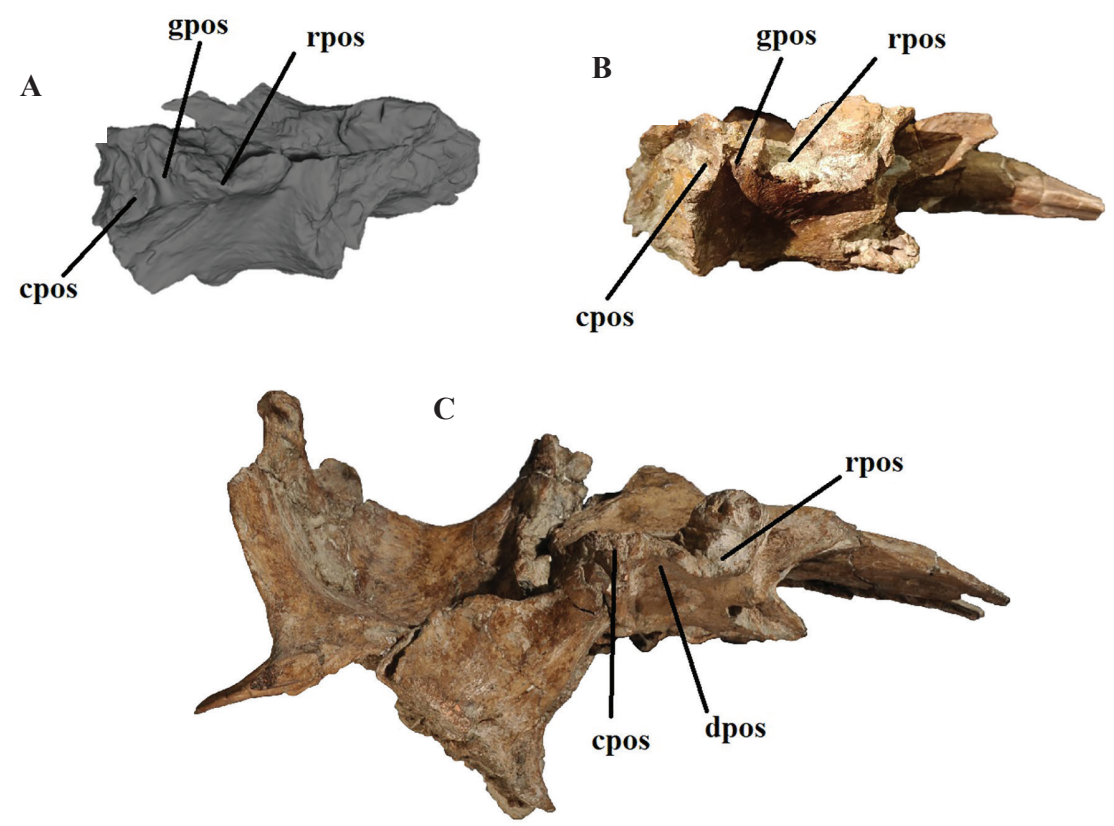

Fig. 2. Frontal bones of tyrannosaurid theropods in right lateral view, scaled to same total length. A, the right frontal of Dynamoterror dynastes UMNH VP 28348 in lateral view. B, the right frontal of Teratophoneus curriei BYU 8120/9396 in lateral view. C, the braincase of Teratophoneus curriei UMNH VP 16690 (reversed) in lateral view. B and C are courtesy of Rod Scheetz and Mark Loewen. Abbreviations: cpos, caudal part of postorbital suture; dpos, depression between rostral and caudal parts of postorbital suture; gpos, groove between rostral and caudal parts of postorbital suture; rpos, rostral part of postorbital suture.

\section{Discussion}

As noted above, the proposed diagnostic features of Dynamoterror dynastes are found in other tyrannosaurid taxa, and highly variable between intraspecific individuals or even positions. Additionally, the poorly preserved nature of the holotype makes it suspicious whether these are comparable to other tyrannosaurids. The frontals of Dynamoterror show one synapomorphy of derived tyrannosaurines that are less derived than Tarbosaurus + Tyrannosaurus clade, a single, dorsoventrally tall sagittal crest (Carr et al., 2017). Thus, a type specimen should be reclassified as Tyrannosaurinae Osborn, 1906 incertae sedis. As such, the taxonomic name Dynamoterror dynastes should be regarded as a nomen dubium.

The challenge of the taxonomic status of "Dynamoterror dynastes" bears several important implications on current taxonomy of tyrannosaurids and naming fossil taxa. Recently, several fragmentary specimens have been interpreted as representing new taxa of tyrannosaurids (e. g., Hone et al., 2011; Fiorillo and Tykoski, 2014). While it is true that these should be considered as taxonomically valid unless the supposed autapomorphies are disputed, historical accounts suggest critical examinations on the degree of intraspecific variation of related taxa should be conducted before providing names for such materials. Generic names such as Stygivenator Olshevsky, 1995, Nanotyrannus Bakker et al., 1988 and Dinotyrannus Olshevsky, 1995 were given to juvenile individuals of Tyrannosaurus rex Osborn, 1905 (Carr, 1999; Carr and Williamson, 2004), even if similar ontogenetic dimorphism in closely related taxon was already described in literature long before the naming of these taxa (Rozhdestvensky, 1965). If such comparisons have been made, it would have provided rejection of most of these unnecessary junior synonyms. Additionally, high degree of intraspecific or positional variations in configuration of suture between frontal and adjacent bones have been noted in various clades of theropods (e. g., Currie and Evans, 2020). Thus, future authors should pay more caution in naming new theropod taxa based on isolated frontal bones. 
It might be argued that although the supposed autapomorphies for "Dynamoterror" may be found in some other tyrannosaurid specimens, it is the unique combination of these features that distinguishes "Dynamoterror" as a valid taxonomic name. However, if this rationale is applied to current tyrannosaurid taxonomy, nearly every specimen of tyrannosaurids that are known for multiple individuals (e. g., Gorgosaurus, Daspletosaurus, and Tyrannosaurus) should be regarded as a distinct taxon. For example, almost every referred specimen of Gorgosaurus and Daspletosaurus differ from holotypes of each taxon in the configuration of sutures surrounding the frontal (e. g., Currie, 1987, 2003; pers. obs.), making it highly dubious whether such characters have a taxonomic merit. Additionally, the incomplete, eroded nature of UMNH VP 28348 frontals makes it dubious whether the ascribed features represent true morphology of complete bones.

The wide range of morphological variations in frontal bone is observable in many theropod species (e. g., Currie, 1987; Barsbold and Osmólska, 1999) and due to this, many authors have expressed great cautions about using such features when diagnosing a theropod taxon (Ibrahim et al., 2020; Smyth et al., 2020). Additionally, Carpenter (2010) suggested that autapomorphies based around minor variation of highly variable regions should be rejected. Thus, the author believes that two autapomorphies suggested for "Dynamoterror" are inadequate regardless of their presence in other taxa, as they are largely based on features that are likely within the degree of individual variation rather than taxonomic. In this approach, it would be wiser to consider "Dynamoterror dynastes" as nomen dubium rather than a valid taxon.

Although UMNH VP 28348 is not sufficient to base a taxon on, it is nevertheless important for representing one of the oldest unambiguous tyrannosaurid materials in the so far known fossil record (McDonald et al., 2018). Given its systematic position as derived tyrannosaurine, and its occurrence at the region what is now New Mexico, the specimen supports the notion that tyrannosaurids were already diversified at least prior or during the early Campanian. And this is additionally supported by presence of Lythronax in Utah and Thanatotheristes in Alberta (Loewen et al., 2013; Voris et al., 2020).

The author thanks Kesler Randall for the permission to study theropod fossils that are housed in the SDNHM. Special thanks go to Rod Scheetz and Mark Loewen for sharing images of tyrannosaurid specimens that were used for comparisons. Casts of UMNH VP 23438 were made by Jin-Kyeom Kim from STL files uploaded in Sketchfab (https://sketchfab.com/WesternScienceCenter/collections/dynamoterror-dynastes) website by Western Science Center, and the author thanks for his help. The author thanks Oleksandr Kovalchuk and one anonymous reviewer for their valuable review comments, which greatly improved the quality of this manuscript. Last, the author's hat is off to Andrew McDonald and his colleagues for their detailed work on UMNH VP 28348. Although our interpretation of the specimen may differ, they nevertheless presented a detailed osteological work that greatly contributed on vertebrate paleontology.

\section{References}

Bakker, R. T., Williams, M., Currie, P. J. 1988. Nanotyrannus, a new genus of pygmy tyrannosaur from the latest Cretaceous of Montana. Hunteria, 1, 1-30.

Barsbold, R., Osmólska, H. 1999. The skull of Velociraptor (Theropoda) from the Late Cretaceous of Mongolia. Acta Palaeontologica Polonica, 44, 189-219.

Bever, G. S., Brusatte, S. L., Carr, T. D., Xu, X., Balanoff, A. M., Norell, M. A. 2013. The braincase anatomy of the Late Cretaceous dinosaur Alioramus (Theropoda: Tyrannosauroidea). Bulletin of the American Museum of Natural History, 376, 1-72.

Brochu, C. A. 2003. Osteology of Tyrannosaurus rex: insights from a nearly complete skeleton and high-resolution computed tomographic analysis of the skull. Society of Vertebrate Paleontology Memoir, 7 (22), 1-138. https://doi.org/10.1080/02724634.2003.10010947

Brusatte, S. L., Norell, M. A., Carr, T. D., Erickson, G. M., Hutchinson, J. R., Balanoff, A. M., Bever, G. S., Choiniere, J. N., Makovicky, P. J., Xu, X. 2010. Tyrannosaur paleobiology: new research on ancient exemplar organisms. Science, 329, 1481-1485. https://doi.org/10.1126/science.1193304

Carpenter, K. 2010. Variation in a population of Theropoda (Dinosauria): Allosaurus from the Cleveland-Lloyd Quarry (Upper Jurassic), Utah, USA. Paleontological Research, 14, 250-259. https://doi.org/10.2517/13428144-14.4.250

Carr, T. D. 1999. Craniofacial ontogeny in Tyrannosauridae (Dinosauria, Theropoda). Journal of Vertebrate Paleontology, 19, 497-520. https://doi.org/10.1080/02724634.1999.10011161 
Carr, T. D., Williamson, T. E. 2004. Diversity of late Maastrichtian Tyrannosauridae (Dinosauria: Theropoda) from western North America. Zoological Journal of the Linnean Society, 142, 479-523. https://doi. org/10.1111/j.1096-3642.2004.00130.x

Carr, T. D., Williamson, T. E., Britt, B. B., Stadtman, K. 2011. Evidence for high taxonomic and morphometric tyrannosauroid diversity in the Late Cretaceous (Late Campanian) of the American Southwest and a new short-skulled tyrannosaurid from the Kaiparow its formation of Utah. Naturwissenschaften, 98, 241-246. https://doi.org/10.1007/s00114-011-0762-7

Carr, T. D., Varricchio, D. J., Sedlmayr, J. C., Roberts, E. M., Moore, J. R. 2017. A new tyrannosaur with evidence for anagenesis and crocodile-like facial sensory system. Scientific Reports, 7, 44942. https://doi.org/10.1038/srep44942

Currie, P. J. 1987. Theropods of the Judith River Formation of Dinosaur Provincial Park, Alberta. In: Currie, P. J., Koster, E. H., eds. Fourth Symposium Mesozoic Terrestrial Ecosystems. Short Papers Tyrrell Museum Palaeontology, 1987, 52-60.

Currie, P. J. 2003. Cranial anatomy of tyrannosaurid dinosaurs from the Late Cretaceous of Alberta, Canada. Acta Palaeontologica Polonica, 48, 191-226.

Currie, P. J., Evans, D. C. 2020. Cranial Anatomy of New Specimens of Saurornitholestes langstoni (Dinosauria, Theropoda, Dromaeosauridae) from the Dinosaur Park Formation (Campanian) of Alberta. The Anatomical Record, 303, 691-715. https://doi.org/10.1002/ar.24241.

Dalman, S. G., Lucas, S. G. 2018. Tyrannosaurid dinosaurs (Theropoda: Tyrannosauridae) from the Upper Cretaceous (early Campanian) Allison Member of the Menefee Formation, New Mexico: implications for the origin of Tyrannosauridae in North America. New Mexico Museum of Natural History and Science Bulletin, 79, 99-112.

Fiorillo, A. R., Tykoski, R. S. 2014. A diminutive new tyrannosaur from the top of the world. PLoS ONE, 9, e91287. https://doi.org/10.1371/journal.pone.0091287

Holtz, T. R., Jr. 2004. Tyrannosauroidea. In: Weishampel, D. B., Dodson, P., Osmolska, H., eds. The Dinosauria: Second Edition. University of California Press, Berkeley, 111-136.

Hone, D. W. E., Wang, W., Sullivan, C., Zhao, X., Chen, S., Li, D., Ji, S., Ji, Q., Xu, X. 2011.A new, large tyrannosaurine theropod from the Upper Cretaceous of China. Cretaceous Research, 32, 495-503. https://doi. org/10.1016/j.cretres.2011.03.005

Ibrahim, N., Sereno, P. C., Varricchio, D. J., Martill, D. M., Dutheil, D. B., Unwin, D. M., Baidder, L., Larsson, H. C. E., Zouhri, S., Kaoukaya, A. 2020. Geology and paleontology of the Upper Cretaceous Kem Kem Group of eastern Morocco. ZooKeys, 928, 1-216. https://doi.org/10.3897/zookeys.928.47517.

Lambe, L. M. 1914. On a new genus and species of carnivorous dinosaur from the Belly River Formation of Alberta, with a description of the skull of Stephanosaurus marginatus from the same horizon. Ottawa Naturalist, 28, 13-20.

Loewen, M. A., Irmis, R. B., Sertich, J. W., Currie, P. J., Sampson, S. D. 2013. Tyrant dinosaur evolution tracks the rise and fall of Late Cretaceous oceans. PLoS ONE, 8, e79420. https://doi.org/10.1371/journal. pone. 0079420

McDonald, A. T., Wolfe, D. G., Dooley, A. C. 2018. A new tyrannosaurid (Dinosauria: Theropoda) from the Upper Cretaceous Menefee Formation of New Mexico. PeerJ, 6, e5749. https://doi.org/10.7717/peerj.5749

Nesbitt, S. J., Denton Jr, R. K., Loewen, M. A., Brusatte, S. L., Smith, N. D., Turner, A. H., Kirkland, J. I., McDonald, A. T., Wolfe, D. G. 2019. A mid-Cretaceous tyrannosauroid and the origin of North American end-Cretaceous dinosaur assemblages. Nature Ecology \& Evolution, 3, 892-899. https://doi.org/10.1038/s41559-019-0888-0

Olshevsky, G. 1995. The origin and evolution of the tyrannosaurids. Kyoryugaku Saizensen (Dino Frontline), 9, 92-119 [In Japanese].

Osborn, H. F. 1905. Tyrannosaurus and other Cretaceous carnivorous dinosaurs. Bulletin of the American Museum of Natural History, 21, 259-265.

Osborn, H. F. 1906. Tyrannosaurus, Upper Cretaceous carnivorous dinosaur (second communication). Bulletin of the American Museum of Natural History, 22, 281-296.

Rozhdestvensky, A. K. 1965. Growth changes in Asian dinosaurs and some problems of their taxonomy. Palaeontological Journal, 3, 95-109 [In Russian].

Russell, D. A. 1970.Tyrannosaurs from the Late Cretaceous of Western Canada. National Museum of Natural Sciences, Publications in Paleontology, 1, 1-34.

Smyth, R. S., Ibrahim, N., Martill, D. M. 2020. Sigilmassasaurus is Spinosaurus: a reappraisal of African spinosaurines. Cretaceous Research, 114, 104520. https://doi.org/10.1016/j.cretres.2020.104520.

Voris, J. T., Zelenitsky, D. K., Therrien, F., Currie, P. J. 2019. Reassessment of a juvenile Daspletosaurus from the Late Cretaceous of Alberta, Canada with implications for the identification of immature tyrannosaurids. Scientific Reports, 9, 17801. https://doi.org/10.1038/s41598-019-53591-7

Voris, J. T., Therrien, F., Zelenitsky, D. K., Brown, C. M. 2020. A new tyrannosaurine (Theropoda: Tyrannosauridae) from the Campanian Foremost Formation of Alberta, Canada, provides insight into the evolution and biogeography of tyrannosaurids. Cretaceous Research, 110, 104388.https://doi.org/10.1016/j.cretres.2020.104388

Zanno, J., Lindsay, E., Tucker, R. T., Canoville, A., Avrahami, H. M., Gates, T. A., Makovicky, P. J. 2019. Diminutive fleet-footed tyrannosauroid narrows the 70-million-year gap in the North American fossil record. Communications Biology, 2, 64. https://doi.org/10.1038/s42003-019-0308-7.

Received 16 March 2020

Accepted 24 April 2020 